\title{
Limitations and trade-offs in the use of species distribution maps for protected area planning
}

\author{
Moreno Di Marco ${ }^{1,2 \star}$, James E. M. Watson ${ }^{2,3}$, Hugh P. Possingham ${ }^{1,4}$ and Oscar Venter ${ }^{1,5}$ \\ ${ }^{1}$ ARC Centre of Excellence for Environmental Decisions, Centre for Biodiversity and Conservation Science, The \\ University of Queensland, Brisbane, 4072 QId, Australia; ${ }^{2}$ School of Geography, Planning and Environmental \\ Management, The University of Queensland, Brisbane, 4072 QId, Australia; ${ }^{3}$ Global Conservation Program, Wildlife \\ Conservation Society, 2300 Southern Boulevard, Bronx, NY 10460, USA; ${ }^{4}$ Department of Life Sciences, Imperial \\ College London, Buckhurst Road, Ascot, Berkshire SL5 7PY, UK; and ${ }^{5}$ Ecosystem Science and Management, \\ University of Northern British Columbia, Prince George, BC V2N 4Z9, Canada
}

\section{Summary}

1. Range maps represent the geographic distribution of species, and they are commonly used to determine species coverage within protected areas and to find additional places needing protection. However, range maps are characterized by commission errors, where species are thought to be present in locations where they are not. When available, habitat suitability models can reduce commission errors in range maps, but these models are not always available. Adopting a coarse spatial resolution is often seen as an alternative approach for reducing the effect of commission errors, but this comes with poorly explored conservation tradeoffs.

2. Here, we characterize these trade-offs by identifying scenarios of protected area expansion for the world's threatened terrestrial mammals under different resolutions (10-200 km) and distribution data deriving from range maps and habitat suitability models.

3. We found that planning new protected areas using range maps results in an overestimation of the species protection level when compared with habitat suitability models (which are more closely related to species presence). This overestimation increases when more area is selected for protection and is higher when higher spatial resolutions are employed.

4. Adopting coarse resolutions reduced the overestimation of species protection and also halved the spatial incongruence between protected areas prioritized from range maps or habitat suitability models. However, this came at a very high cost, with an area of up to four times greater $\left(12 \mathrm{M} \mathrm{km}^{2}\right.$ vs. $\left.3 \mathrm{M} \mathrm{km}^{2}\right)$ needed to adequately protect all species.

5. Synthesis and applications. Our findings demonstrate that adopting coarse resolutions in protected area planning results in unsustainable increases in costs, with limited benefits in terms of reducing the effect of commission errors in species range maps. We recommend that, if some level of uncertainty is acceptable to practitioners, using range maps at resolutions of $20-30 \mathrm{~km}$ is the best compromise for reducing the effect of commission errors while maintaining cost-efficiency in conservation analyses.

Key-words: commission errors, conservation planning, geographic range, habitat suitability model, IUCN range maps, protected area planning, spatial conservation prioritization, spatial resolution, species distribution, threatened species

\section{Introduction}

Conservation efforts at all scales are influenced by the knowledge of where species are distributed (Margules \& Pressey 2000; Whittaker et al. 2005). Maps of the

*Correspondence author. E-mail: m.dimarco@uq.edu.au distribution of species are commonly used to determine their coverage within protected areas, and to find where new protected areas need to be placed (Venter et al. 2014; Watson et al. 2014; Butchart et al. 2015). These maps are also used to determine local-scale priorities for conservation actions (Wilson et al. 2007; Carwardine et al. 2008b). Similarly, the investigation of macroecological patterns is 
necessarily based on our knowledge of past and present species distributions (Orme et al. 2006; Di Marco \& Santini 2015; Faurby \& Svenning 2015).

Long-standing debate has focused on the most appropriate methodologies to follow for creating and using distribution maps in conservation and ecological analyses (Rondinini et al. 2006; Gaston \& Fuller 2009; Guisan et al. 2013; Joppa et al. 2015). In addition, recent international commitments to expand the global protected area (PA) network (Watson et al. 2014) are stimulating ever increasing research on the use of species distribution maps to inform PA expansion (McCarthy et al. 2012; Montesino Pouzols et al. 2014; Venter et al. 2014; Butchart et al. 2015). Underpinning much of this work are geographic ranges, or simply 'ranges', mapped by the Red List of the International Union for Conservation of Nature (IUCN). These are the most comprehensive (taxonomically and geographically) data on the global distribution of tens of thousands of species (IUCN 2015). These maps have been repeatedly used in global and regional conservation analyses, often to identify gaps in PA coverage and priorities for PA expansion (Rodrigues et al. 2004; Venter et al. 2014).

Despite the increasing completeness and availability of species range data sets, our knowledge of the geographic distributions of species remains inadequate (Whittaker et al. 2005; Pimm et al. 2014). A key issue is that range maps are coarse representations of species distributions, and they are particularly prone to commission errors, where species are thought to be present in locations where they are actually absent (Rodrigues et al. 2004; Rondinini et al. 2006; Jetz, Sekercioglu \& Watson 2008). This issue can have significant impacts on how conservation priorities are set. Commission errors can result in an overestimation of PA coverage for some species and can lead to the identification of priority areas that do not actually contain the species that triggered the priority listing. In addition, overestimating species distributions can result in an overoptimistic assessment of their extinction risk if the actual ranges are substantially smaller than expected. Range maps are also prone to omission errors, that is overlooking areas which are actually occupied by the species. However, these errors are not analysed here, since they are mostly relevant for groups with localized distributions, such as amphibians, and their influence in conservation assessments has already been discussed elsewhere (Ficetola et al. 2014).

Two main approaches have been adopted to deal with commission errors when using species range maps: (i) performing analyses at a coarse resolution and (ii) using refined habitat suitability models. In the first case, coarse grid resolutions are used, for example 1 or 2 degrees (Hurlbert \& Jetz 2007), to reduce the probability of including unoccupied grid cells as part of a species' distribution. This is not in itself a solution to the problem, rather it is a way to minimize its effects. A wide spectrum of spatial resolutions are still commonly employed for analysing species range maps, with the most common values ranging from $10 \mathrm{~km}$ (Wilson et al. 2011) to $200 \mathrm{~km}$ (Hurlbert \& Jetz 2007) grid cells. This heterogeneity in resolution has important theoretical and practical conservation implications. In the second case, commission errors are reduced by removing unsuitable habitat from species range maps, using expert-based or statistically derived relationships between species presence and environmental characteristics (Rondinini, Stuart \& Boitani 2005; Jetz, Wilcove \& Dobson 2007). This way, the likelihood of including unoccupied areas in a conservation plan can be much reduced, thus minimizing the likelihood of commission errors.

Habitat suitability models, or extensive survey data (Di Marco et al. 2016), are not always available, and therefore coarse spatial resolutions are often employed when using range maps suffering from commission errors (Hurlbert \& Jetz 2007). The effect of changing resolution when using range maps for analysing macroecological patterns (such as species richness) has been investigated (Rahbek 2005; Pineda \& Lobo 2012). Similarly, the effect of overestimating species ranges due to commission errors has been assessed at different scales (Jetz, Sekercioglu \& Watson 2008). However, the trade-off associated with the use of different spatial resolutions and how these are influenced by different species distribution proxies (e.g. habitat models vs. range maps) is yet to be investigated in the context of conservation planning. Assessing this trade-off will allow conservation decisionmakers to better navigate the decision between increasing the efficiency of a conservation plan, by performing analyses at a fine resolution, vs. reducing uncertainty in the use of range maps with commission errors, by performing analyses at a coarse resolution. After decades of development of species distribution maps, guidelines of how to use these maps for conservation planning are still missing.

We measured the effect of different spatial resolutions on the identification of priority areas for PA expansion, using different distribution proxies - IUCN range maps and habitat suitability models - to measure species coverage within PAs. We employed analytical resolutions ranging from $10 \mathrm{~km}$ to $200 \mathrm{~km}$ (Fig. 1), which are typically used in global conservation and ecological analyses (Ceballos et al. 2005; Hurlbert \& Jetz 2007; Carwardine et al. 2008a; Wilson et al. 2011; Venter et al. 2014). We focused our analyses on threatened terrestrial mammals, since both distribution data types (ranges and habitat models) are comprehensively available for this group and they represent, together with birds, the taxonomic group attracting the most attention in conservation science (Clark \& May 2002; Lawler et al. 2006), providing a good study case for other groups. We identified priority areas for PA expansion using a conservation planning approach, where our aim was to find the minimum set of additional area to be protected in order to achieve an adequate level of coverage for all species. 


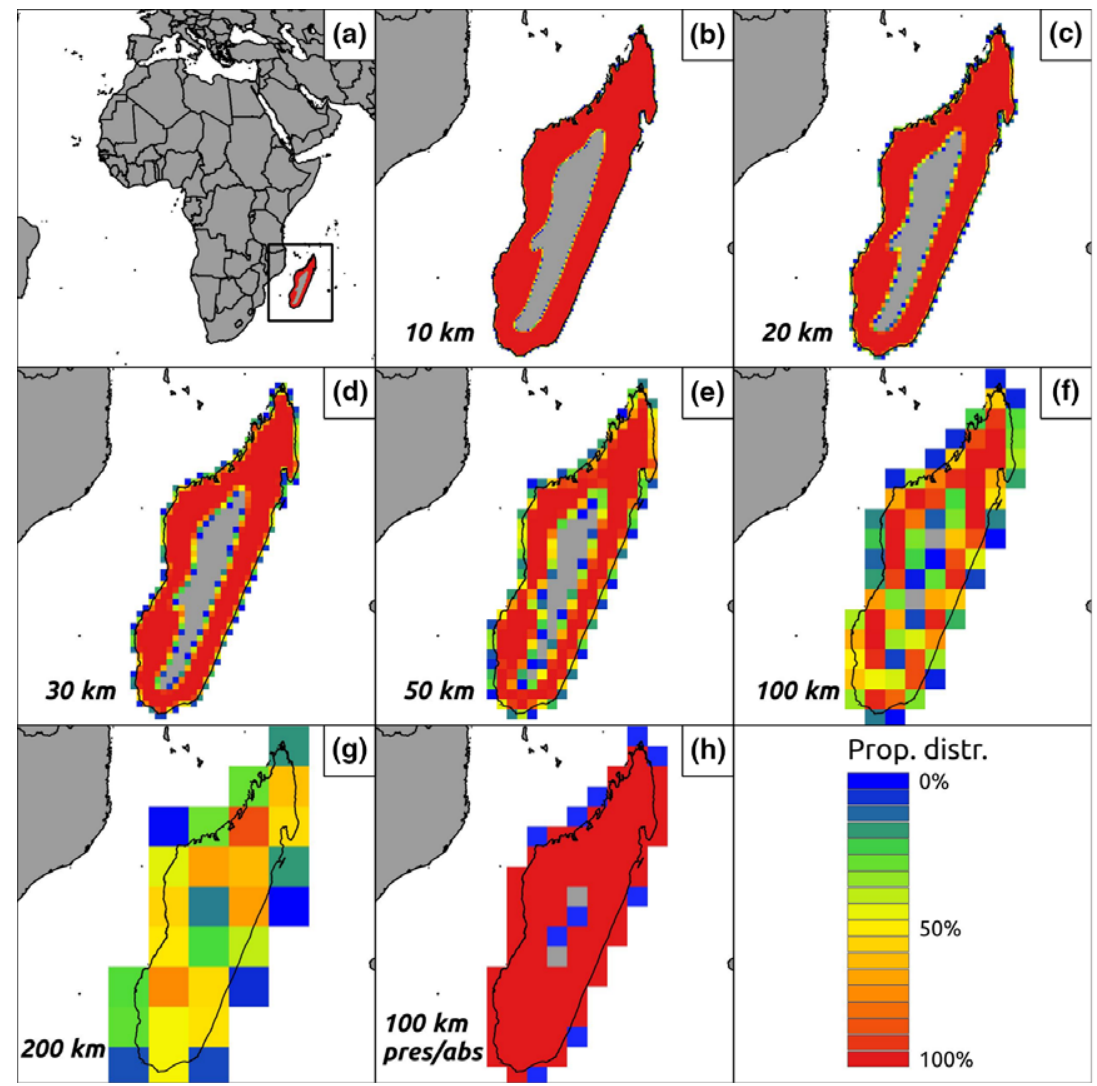

Fig. 1. Spatial distribution of the fossa (Cryptoprocta ferox), a threatened Madagascan mammal. Panel (a) shows the global location of the species range. Panels (b-g) show the proportion of species geographic range within grid cells at various resolutions (from $10 \mathrm{~km}$ to $200 \mathrm{~km}$ ). Panel (h) shows a binary reclassification (presence/absence) of the species range at a $100 \mathrm{~km}$ resolution; in this case a cell was considered to be entirely occupied if $\geq 5 \%$ of its area overlapped with the species range, and entirely unoccupied otherwise. The colour scale is the same for all panels. [Colour figure can be viewed at wileyonlinelibrary.com].

\section{Materials and methods}

\section{DISTRIBUTION DATA}

We analysed distribution data for $1115(99.5 \%)$ species of threatened terrestrial mammals with available distribution information. Following previous studies (Venter et al. 2014), we focused our analyses on threatened species, because these are the species of highest conservation concern and typically targeted by international conventions (Secretariat of the CBD 2010).

We obtained geographic range maps from the IUCN Red List (IUCN 2015) and habitat suitability models from the Global Mammal Assessment program (https://globalmammal.org/habitat -suitability-models-for-terrestrial-mammals/). IUCN range maps represent the global distribution of species and include all areas where a species is found to occur permanently or periodically. Following previous works (Venter et al. 2014; Butchart et al. 2015), we removed areas where species exist outside their native ranges, and areas where species were considered to be extinct (i.e. areas that were part of the historical range but not part of the current range).

Range maps can include areas which are unable to sustain viable populations and are only used occasionally by the species (e.g. during dispersal movements). In contrast, expert-based habitat suitability models are deductive classifications of species habitat requirements, based on information retrieved from the literature, and allow the identification of suitable and unsuitable areas within the species ranges. The habitat suitability models used in our study were described in Rondinini et al. (2011), who employed a systematic classification of the species' habitat preferences reported in the IUCN Red List data base (IUCN 2015).
The models were based on the following: species' preferences for land cover type and their tolerance to human settlements, mapped using Globcover (Bontemps et al. 2011); species' altitudinal limits, mapped from the Shuttle Radar Topography Mission elevation (USGS 2006); species' relationship with water bodies, mapped from Globcover and Vmap0 (National Imagery and Mapping Agency 1997). For 102 species in our sample $(<9 \%)$, the entire range was considered suitable because they had a geographic range smaller than $100 \mathrm{~km}^{2}(n=83)$, which also corresponds to the smallest planning units size adopted in our spatial prioritization analysis (see below), or because the information on habitat preferences was missing $(n=19)$ (Rondinini et al. 2011).

We used the July 2015 version of the World Database on Protected Areas to measure the current level of species coverage within PAs (IUCN \& UNEP-WCMC 2015). We considered all designated terrestrial PAs associated with an IUCN category of management (from I to VI). These included areas with a defined spatial shape $(n=125430)$ and areas represented as buffered centroids $(n=11$ 997). All spatial maps (ranges, habitat suitability models and protected areas) were initially rasterized at a $300 \mathrm{~m}$ resolution, that is the native resolution of habitat suitability models. The maps were subsequently resampled at coarser analytical resolutions, using cell sizes typically employed in global-scale analyses: $10 \mathrm{~km}, 20 \mathrm{~km}, 30 \mathrm{~km}, 50 \mathrm{~km}, 100 \mathrm{~km}$ and $200 \mathrm{~km}$. To resample the data at a coarser resolution, we measured the proportional species occupancy of each grid cell by overlapping high-resolution maps of species distribution and obtained continuous values ranging from $0 \mathrm{~km}^{2}$ to the maximum of the cell size; a graphical representation of the resampling process is provided in Fig. 1. We also tested the effect of using a binary, rather than continuous, resampling technique, where each cell was considered 
to be either occupied or not (Ceballos et al. 2005). In this case, we set a minimum threshold of $5 \%$ of the cell overlapping with a species' distribution map in order for it to be considered occupied, to exclude marginal overlaps from the analyses (Fig. 1h).

All spatial analyses were performed in a Mollweide equal-area projection, with the software GRASSGIS (GRASS Development Team 2014).

\section{SPATIAL PRIORITIZATION ANALYSIS}

We defined global grids at various resolutions (from $10 \mathrm{~km}$ to $200 \mathrm{~km}$, described above) and resampled the distribution of species and PAs in each grid cell. For each grid cell, we measured the extent of species' geographic range and the extent of species' suitable habitat [including both medium and high suitability; (Rondinini et al. 2011)], within and outside of PAs. In this way, we were able to measure the total extent of protected and unprotected species distribution. We used the total distribution of species to calculate representation targets, following Rodrigues et al. (2004) and subsequent applications (Venter et al. 2014; Butchart et al. 2015), according to the following formulation:

Target $=\operatorname{MAX}(0 \cdot 1, \operatorname{MIN}(1,-0 \cdot 375 \times \log 10($ range size $)+2 \cdot 126))$

Widespread species with a global geographic range larger than $250000 \mathrm{~km}^{2}$ were assigned a fixed target of $10 \%$. Small-ranged species with a global geographic range smaller than $1000 \mathrm{~km}^{2}$ were assigned a fixed target of $100 \%$. Intermediate-ranged species were assigned a target value which was loglinearly interpolated between the two thresholds. The current PA coverage was used to calculate the shortfall between current level of protection and the desired level of protection (represented by the targets).

We performed global-scale spatial prioritization analyses to identify the places where the shortfall in current levels of species protection could be covered with a minimal additional area. We used Marxan (Ball, Possingham \& Watts 2009), a spatial prioritization software, to identify spatial priorities for PA expansion. We treated grid cells as planning units, and let the new PAs be selected only among the unprotected portion of each grid cell. For each scenario and for each resolution (described below), we performed one Marxan run with one billion iterations and no boundary length modifier (Venter et al. 2014). We then defined a coverage curve by incrementally expanding the global PA network up to $x \mathrm{~km}^{2}$, where $x$ is the total area required to achieve adequate PA coverage for all species (and $x$ is different for different resolutions). For each increment, we measured the aggregate proportion of representation targets met, which we referred to as 'species coverage'. We also measured the level of spatial overlap between the priority areas identified under the three scenarios, at various resolutions (fine to coarse)

\section{SCENARIOS SETTING}

We defined three analytical scenarios, based on the use of habitat suitability models and geographic range maps to represent species distributions (Table 1). In the first scenario, 'perceived coverage', we used range maps to identify priority sites for PA expansion and to measure the achievement of species targets. We considered this coverage as 'perceived', as opposed to 'realized' (see below), because the presence of commission errors in range maps may result in an overestimation of the actual level of species coverage achieved. This is the scenario typically employed in global-scale spatial prioritization analyses (Rodrigues et al. 2004; Montesino Pouzols et al. 2014; Venter et al. 2014; Butchart et al. 2015).

In the second scenario, 'realized coverage', we used range maps to identify priority sites for PA expansion and habitat suitability models to measure the achievement of species targets. We considered this coverage as 'realized', because only the areas where the species is expected to occur are considered when measuring the achievement of targets. This corresponds to an evaluation of the actual coverage achieved (in terms of represented suitable habitat) when employing a coarse distribution proxy such as geographic range.

In the third scenario, 'suitable coverage', we used habitat suitability models to identify priority sites for PA expansion and to measure the achievement of targets. In this case, the priority sites for PA expansion are directly targeted to the representation of suitable habitat. This scenario is equivalent to targeting the areas where a species is most likely to occur, and measuring PA coverage only for these areas.

For each of the three scenarios, and for each separate resolution settings, we defined curves of the relationship between area covered and cumulative levels of species targets achieved (which we refer to as 'species coverage'). We also compared these scenarios with a 'random coverage' scenario, representing a null model of protected area expansion where no knowledge of species distribution is assumed. In this case, planning units were selected at random to achieve the same cumulative levels of protected area expansion as for the realized scenario. To represent the coverage achieved under this scenario, we defined 100 random planning unit samples for each cumulative level of protected area expansion and extracted the median coverage across all the samples.

\section{SENSITIVITY TESTING}

We verified the sensitivity of our results to alternative settings of the spatial resampling procedure and spatial prioritization analysis. In our analyses, we associated fine-grain information with each grid cell, in the form of proportional distribution data (i.e. proportion of species range within each grid cell). An alternative, and less time-consuming, approach would be to reclassify all data as binary presence/absence values, especially when coarse resolutions are adopted. To test the effects of this alternative approach, we adopted a binary resampling technique at a commonly used coarse resolution of $100 \mathrm{~km}$ (Ceballos et al. 2005). We also verified the sensitivity of our trade-off curves to the use of a different formulation of the species representation target, by applying fixed targets of $20 \%$ to all species (Di Marco et al. 2016), at a

Table 1. Scenarios of species coverage, obtained by the use of geographic ranges or suitable habitat models for spatial prioritization and for measuring species coverage (i.e. achievement of species' targets)

\begin{tabular}{lll}
\hline & $\begin{array}{l}\text { Measuring } \\
\text { coverage: range }\end{array}$ & $\begin{array}{l}\text { Measuring coverage: } \\
\text { suitable habitat }\end{array}$ \\
\hline Spatial planning: range & $\begin{array}{c}\text { Perceived } \\
\text { coverage } \\
\text { N/A }\end{array}$ & Realized coverage \\
$\begin{array}{l}\text { Spatial planning: } \\
\text { suitable habitat }\end{array}$ & Suitable coverage \\
\hline
\end{tabular}


commonly used intermediate resolution of $30 \mathrm{~km}^{2}$ (Venter et al. 2014). Finally, we verified whether our trade-off curves showed a consistent pattern when using agricultural opportunity cost (Naidoo \& Iwamura 2007), rather than total land area, as a cost layer for the spatial prioritization.

\section{Results}

We found that 165 out of 1115 threatened terrestrial mammals have a geographic range already adequately covered with PAs, meaning that their proportional representation targets are already achieved, while 247 species have an extent of suitable habitat already adequately covered with PAs. When plotting the relationship between protected area expansion and increased species coverage, we found similar nonlinear shapes under all the scenarios and for each analytical resolution (Fig. 2). These curves showed that a high level of species coverage is achievable with a small efficient expansion of the protected area network, in contrast to the small linear increase in coverage that would be expected under a null model of PA expansion (Fig. S1, Supporting Information). We found that the realized level of coverage from new PAs, measured using habitat suitability models, was lower than the perceived level of coverage (Fig. 2). This difference was evident when $>30 \%$ of the total PA expansion was reached, and increased with increasing PA expansion, until the complete perceived coverage was achieved. For example, at a resolution of $10 \mathrm{~km}$ the difference between perceived and realized coverage corresponded to 14 species with a PA expansion of 1.3 million $\mathrm{km}^{2}$ and 28 species with an expansion of $3 \cdot 1$ million $\mathrm{km}^{2}$.

The gap between perceived and realized coverage introduces a level of uncertainty regarding which and how many species will be adequately covered when planning new PAs using range maps. The suitable level of coverage, obtained using habitat suitability models, was always higher than the perceived and realized levels for a similar cost. This highlights the fact that suitable habitat is not randomly distributed within the species ranges, and selecting a few highly suitable planning units would allow a rapid achievement of the species targets. This also indicates that planning new PAs using species range maps results in a coverage which is lower than expected, and lower than possible if using refined information on where species are most likely located.
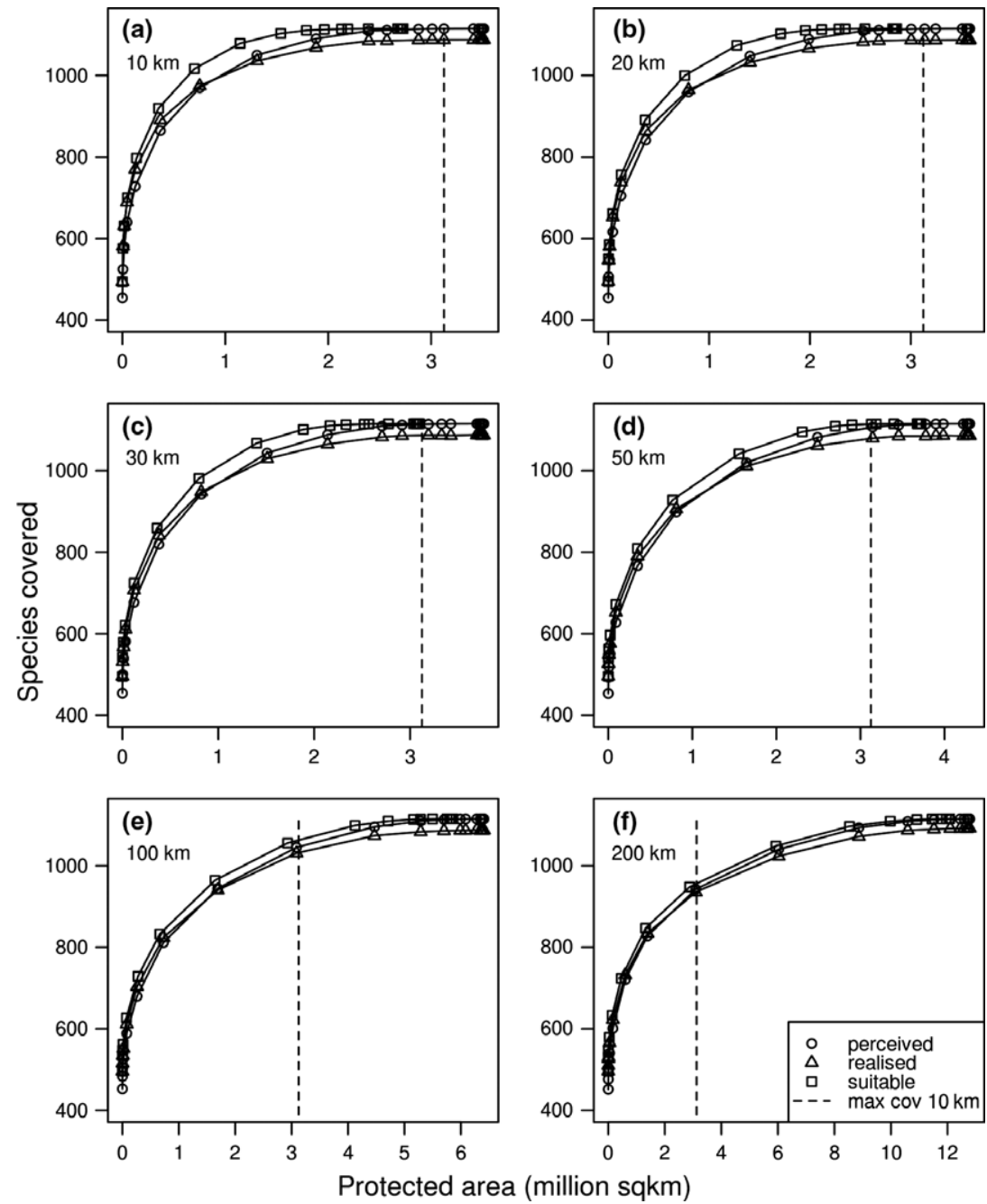

Fig. 2. Trade-off between total area prioritized for protection and aggregate level of species coverage (i.e. sum of species targets achieved). The trade-off curves represent the three scenarios (perceived, realized and suitable) described in Table 1. Data in plots $(\mathrm{a}-\mathrm{f})$ refer to different analytical resolutions, as specified in the plot. Note that the $x$-axes in different panels have different scales, and the dashed vertical line represents the minimum area required to achieve maximal coverage at a $10-\mathrm{km}$ resolution (reported in all panels for reference). 
There were some benefits though to employing coarser analytical resolutions, which tended to lead to a slightly reduced level of uncertainty in the use of range distribution data. This reduced uncertainty was represented by a higher level of correspondence between the perceived and the realized levels of coverage (Fig. 2). In fact, expanding the global PA network by 3.1 million $\mathrm{km}^{2}$ at a $10-\mathrm{km}$ analytical resolution resulted in a perceived level of coverage of 1115 species (i.e. all species targets were met), and a realized level of coverage of 1087 species (difference $=28$ species). When applying the same extent of PA expansion (i.e. $3 \cdot 1 \mathrm{M} \mathrm{km}^{2}$ ) under a $200-\mathrm{km}$ resolution, the difference in coverage between these two scenarios was reduced to 7 species (perceived $=942$ species, realized $=935$ species).

Importantly, the use of coarser analytical resolutions resulted in a substantial increase in the area required to meet species targets. When analyses were performed at a $10-\mathrm{km}$ resolution under the perceived coverage scenario (i.e. based on range maps), we found that 3.1 million $\mathrm{km}^{2}$ of additional PAs were required to achieve an adequate coverage for all species. In contrast, when a $200-\mathrm{km}$ resolution was employed, we found that a fourfold increase in the additional reserve area $\left(12 \cdot 1\right.$ million $\left.\mathrm{km}^{2}\right)$ was required to achieve an adequate coverage for all species. We found a nonlinear relationship between the use of a coarser analytical resolution and the total area required to achieve the desired level of species coverage, both under the perceived coverage scenario and the suitable coverage scenario (Fig. 3). The difference between these two scenarios was larger at a resolution of $10 \mathrm{~km}$ and smaller at coarser resolutions, while the increase in the total area required was higher for resolutions coarser than $30 \mathrm{~km}$.

We mapped the spatial priorities for PA expansion required to achieve complete species coverage under the perceived (i.e. range based) and suitable (i.e. habitat based) scenarios (Fig. 4, see also Figs S2-S4). Spatial priorities determined a partial overlap between the scenarios, identifying three cases: areas selected only under the perceived scenario, areas selected only under the suitable scenario and areas selected under both scenarios (i.e. shared solution). A relationship was observed between coarser analytical resolution and increased amount of shared solution. In particular, analyses performed at a resolution of $200 \mathrm{~km}$ resulted in proportionally twice as much protected area being shared between the perceived and suitable scenario with respect to analyses performed at a $10-\mathrm{km}$ resolution. This means that analyses done at a coarser resolution were less likely to produce spatial mismatch when using different types of distribution data (range maps or habitat models).

When reclassifying distribution data as binary presence/ absence values, we observed a large difference (an overestimation) in the measure of perceived species coverage. In fact, a much higher level of perceived species coverage was found when using presence/absence data rather than

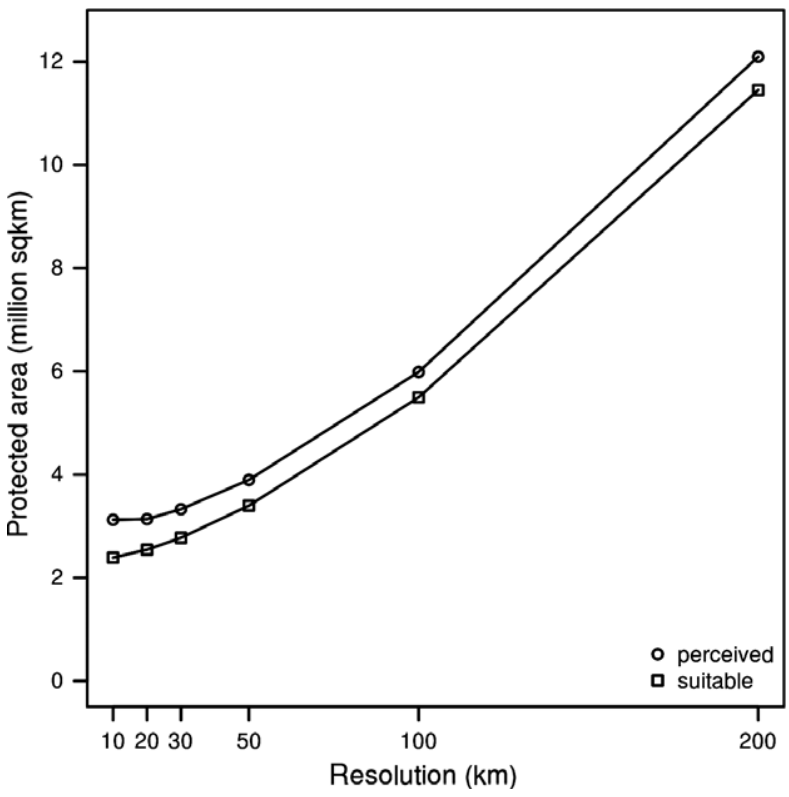

Fig. 3. Relationship between the analytical resolution employed and the total protected area required to achieve the desired level of species coverage. Both the perceived coverage scenario, based on species ranges, and the suitable coverage scenario, based on habitat suitability models, are represented.

proportional distribution data, for the same increment of PAs (Fig. S5). This is due to the consideration of cells as being entirely occupied by a species, when at least a significant portion was occupied. This means that, under a naive resampling technique, many species might be perceived to be adequately covered with PAs when they are actually not. When employing a fixed target formulation (20\% for all species) for identifying priorities for PA expansion, we did not find a significant change in the shape of the area-coverage relationships or in the respective position of the scenarios in the plot (Fig. 5). The only noticeable difference with respect to the use of proportional targets scaled with range size was that in this case the scenarios achieved near-complete levels of coverage much more rapidly. For example, coverage of 1039 species was achieved with a PA expansion of 715 thousand $\mathrm{km}^{2}$ under the fixed target formulation, while only 943 species were covered with a PA expansion of 822 thousand $\mathrm{km}^{2}$ under a scaled target formulation. However, the achievement of complete coverage (i.e. all 1115 targets met) required a larger area under the fixed target formulation $\left(5.8\right.$ million $\left.\mathrm{km}^{2}\right)$ than under the scaled target formulation $\left(3 \cdot 3\right.$ million $\left.\mathrm{km}^{2}\right)$. Finally, we did not find substantial differences in the trade-off curves when using agricultural opportunity cost (instead of spatial extent) as a surrogate of PA expansion cost (Fig. S6).

\section{Discussion}

In this study, we systematically investigated the shortfalls and proposed approaches for use of species range maps 
with commission errors. Our results illustrate a clear relationship between analytical resolution, data type, uncertainty in measuring PA coverage and cost-effectiveness of a spatial prioritization plan. We found that using species range maps at coarse vs. fine analytical resolutions has important conservation implications and trade-offs. At finer analytical resolutions, the spatial prioritization was very efficient in identifying the most strategic areas for PA expansion and required less total area to meet all species representation targets. However, we also discovered that this increased efficiency was associated with slightly higher uncertainty in the use of range maps, resulting in a perceived level of coverage higher than the realized level of coverage (as measured on suitable habitat). At coarser analytical resolutions, up to four times more area had to be selected to achieve complete species coverage, but the uncertainty associated with the use of species range maps was reduced. This has significant ramifications for planners using range maps for conservation applications: although a coarser resolution reduces the uncertainty deriving from commission errors, it also leads to a much larger area being selected to achieve the same level of protected area coverage for species. Moreover, this does not necessarily imply that a much larger suitable area is selected.

The identification of spatial priorities for PA expansion resulted in partially different areas being selected when using geographic range maps or habitat suitability models. Importantly, the mismatch in these spatial configurations was higher at finer resolutions and lower at coarser resolutions. This means that the spatial uncertainty associated with the use of geographic range maps is generally more evident at a local scale, while there is less uncertainty in the identification of larger regions at a broader scale. However, because conservation actions are typically implemented at a local scale (Boyd et al. 2008), the
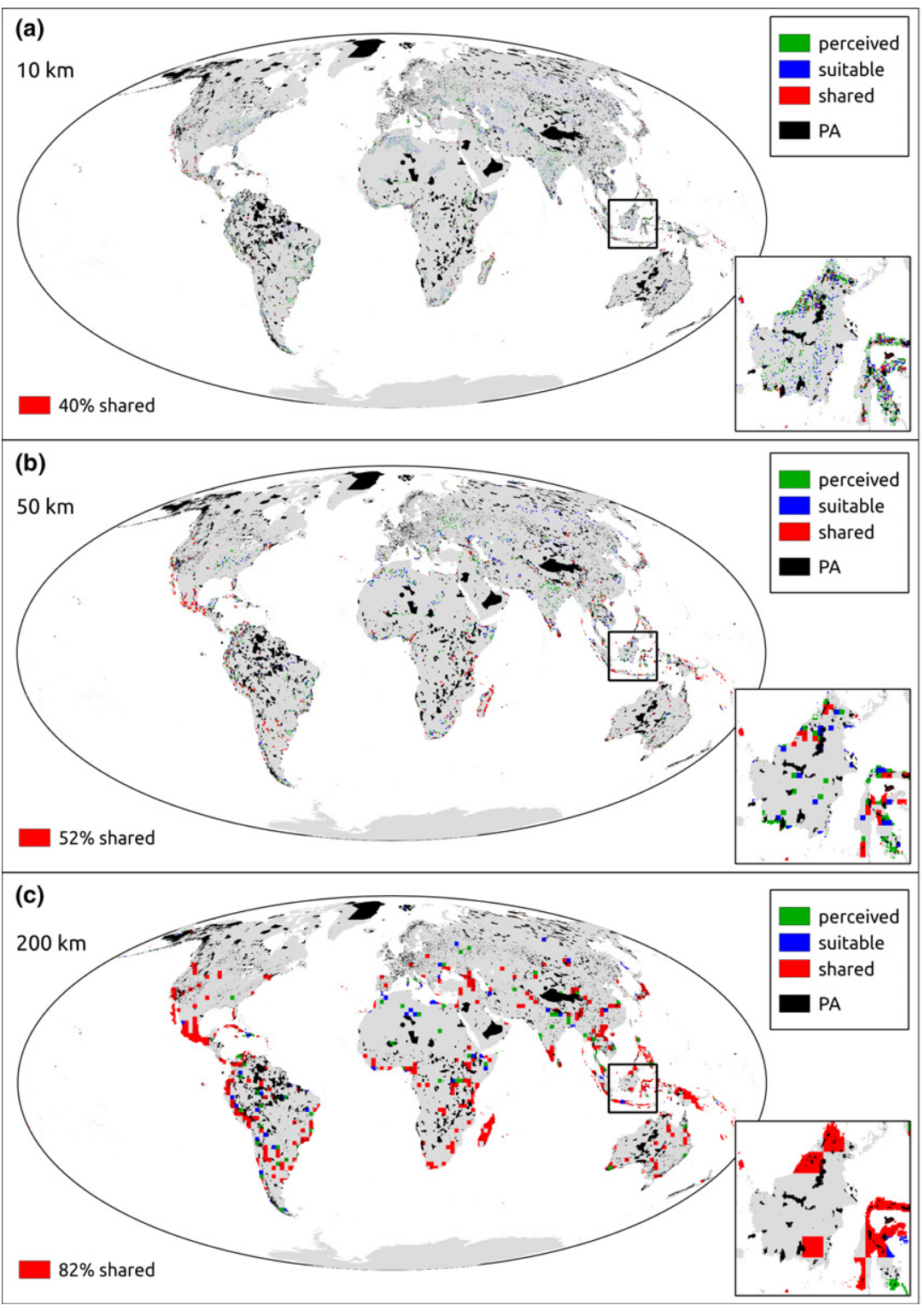

Fig. 4. Spatial solutions to achieve species representation targets under the perceived and suitable scenarios. Under both scenarios, the solution able to achieve complete species coverage with a minimum area was selected. Some of the grid cells are selected only under the perceived scenario or the suitable scenario and others are selected in both scenarios and thus part of a 'shared' solution. The numbers reported on the bottom left of each panel refer to the percentage area of the perceived scenario, which was also selected under the suitable scenario (i.e. the shared solution). Panels refer to results obtained under the following analytical resolutions: (a) $10 \mathrm{~km}$; (b) $50 \mathrm{~km}$; (c) $200 \mathrm{~km}$. An inset map, with details of the South-East Asian region, is reported on the bottom right of each panel for visual reference. A larger version of the maps is reported in Figs S2-S4. [Colour figure can be viewed at wileyonlinelibrary.com]. 
Fig. 5. Trade-off between total area prioritized for protection and aggregate level of species coverage (i.e. sum of species targets achieved) when employing different target formulations. The trade-off curves represent the three scenarios (perceived, realized and suitable) described in Table 1. Data in different plots refer to spatial priorities obtained under different target formulations: (a) proportional representation targets scaled to species range size and (b) fixed $(20 \%)$ proportional representation targets applied to all species. Analyses were performed at a resolution of $30 \mathrm{~km}$.

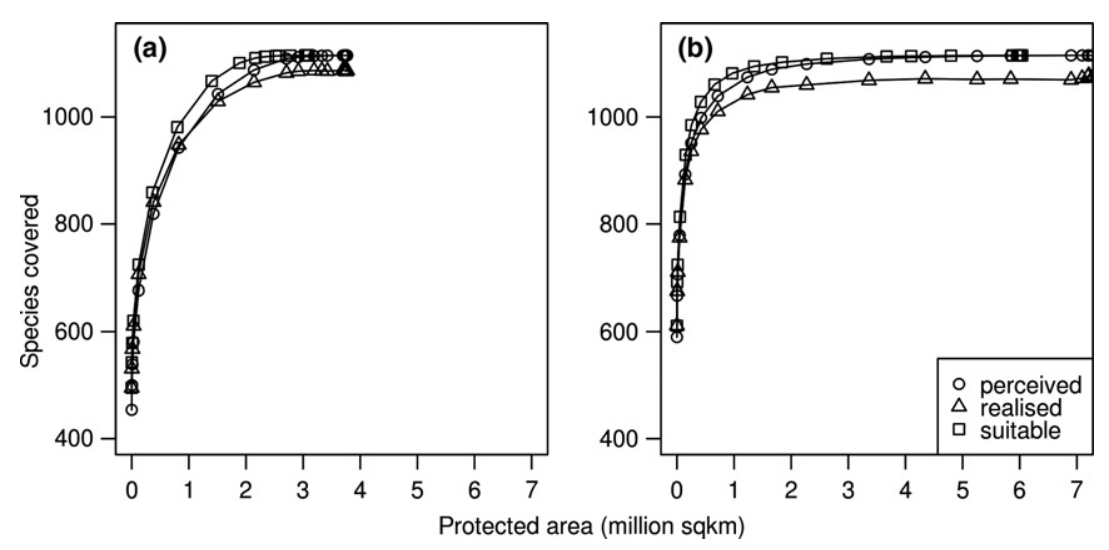

concordance of priority patterns at a very coarse resolution is likely to have little practical advantages.

Similar to previous studies (Venter et al. 2014), we found a nonlinear relationship between incremental PA coverage and incremental coverage of species distribution (i.e. a curve). In this relationship, high levels of species coverage are rapidly achieved when a relatively small amount of strategically located PAs is added to the network. However, to achieve complete coverage (i.e. all species adequately covered with PAs), a relatively large area is required. We found very similar curves when employing fixed representation targets or scaled representation targets, and when adopting land area or agricultural value as surrogate of PA costs. This indicates that our results were robust to the perturbations to the planning problem (i.e. different definitions of targets and costs). Under fixed, rather than scaled, targets, the species rapidly reached a near-complete coverage and then slowly progressed to complete coverage. This is related to the fact that the vast majority of species $(80 \%)$ were associated with a scaled target larger than the adopted fixed target $(20 \%)$. As a consequence, the spatial selection algorithm required less area to achieve the fixed target of these species. However, the remaining species had a scaled target lower than the fixed target (down to half of it). Achieving a 20\% fixed representation target for these widespread species was spatially demanding, consequently almost twice as much area was necessary in the end to achieve complete coverage under the fixed target formulation.

Preventing the decline and extinction of threatened species is a priority goal for conservation interventions (Venter et al. 2014) and an explicit target of international biodiversity conventions (Secretariat of the CBD 2010). Terrestrial mammals represent one of the best studied animal groups and a perfect case for our analyses, since comprehensive distribution ranges (IUCN 2015) and habitat suitability models (Rondinini et al. 2011) are available for these species. This allowed us to identify trade-offs in the use of distribution maps at different analytical resolutions which can be applied to groups with less information available. The use of habitat suitability models allowed us to remove a substantial part $[45 \%$ on average (Rondinini et al. 2011)] of the unsuitable habitat found within the geographic range of mammal species. This unsuitable habitat is likely associated with the perception of false presence (commission error). We acknowledge that habitat suitability maps are model outputs and thus are also prone to some level of commission error, in case the species are not present in suitable habitat (Brooks, da Fonseca \& Rodrigues 2004). However, this issue is much less prominent in habitat models than in range maps, as demonstrated through independent validation (Rondinini et al. 2011; Maiorano et al. 2013). Ultimately, the usefulness of high-resolution models depends on the quality of data used to build them (Rondinini et al. 2006), and that collection of new data on distribution and habitat will improve the quality of these maps and their efficiency for conservation.

In our paper, we did not deal with omission errors (false absences), which may be caused by a species occupying areas outside its mapped geographic range. This is acceptable for mammal species, for which commission errors are the main issue. For groups characterized by a more limited knowledge of their distribution, such as amphibians, the level of omission error can be more substantial (Ficetola et al. 2014). In this case, an additional trade-off element will be present in the choice of an appropriate analytical resolution, and it may be necessary to extend species range maps by a certain buffer around known locations, to avoid overlooking areas of potential species presence (Ficetola et al. 2014). Previous analyses showed that the use of habitat suitability models can introduce omission errors within a species' range (Beresford et al. 2011), if species occupy habitats classified as unsuitable. While commission error can lead to a false sense of species coverage with protected areas, omission errors can reduce the options available for additional protection. However, it has been argued that the former have much higher associated risk than the latter for protected area planning (Rondinini et al. 2006), potentially driving conservation investments towards areas where species are not actually present. The use of species distribution models, rather than expert-based habitat suitability models, can allow controlling the balance between commission and omission errors, by selecting thresholds to define suitable vs. unsuitable habitat (Guisan et al. 2013). However, 
these models are more data demanding and are typically available only for a subset of species, rather than entire species groups.

Errors in spatial data sets (e.g. distributions of species, habitats or protected areas) need careful consideration, as these can lead to misleading assessments of conservation progresses (Visconti et al. 2013). It has been suggested that species range maps should be analysed at a coarse resolution (e.g. $2^{\circ}, \sim 200 \mathrm{~km}$ ) when investigating macroecological patterns (Hurlbert \& Jetz 2007), in order to avoid misleading results due to the overestimation of actual species occupancy. Our results demonstrates that a coarser analytical resolution would also lead to reduced uncertainty in conservation analyses, both in terms of reduced overestimation in species PA coverage and in terms of reduced mismatch between spatial priorities identified using range or habitat models. However, we also found that performing analyses at a coarse resolution is highly inefficient when the objective is to identify spatial priorities for PA expansion. Achieving the desired level of species coverage at a resolution of $200 \mathrm{~km}$ required a PA expansion of 12.1 million $\mathrm{km}^{2}$, four times more than when using a $10-\mathrm{km}$ resolution. This would lead to unnecessarily high expenditure in PA expansion and could present a serious barrier to conservation efforts, since that figure is six times larger than what world governments have currently committed to in terms of terrestrial PA coverage (Secretariat of the CBD 2010; Juffe-Bignoli et al. 2014).

For regional- and global- scale conservation analysis of well-studied groups, such as mammals, we suggest that employing a relatively high analytical resolution (such as $10 \mathrm{~km}$ ) and using refined distribution models is the most appropriate choice (Kark et al. 2009; Wilson et al. 2011). For less well-studied groups, habitat suitability models might not be comprehensively available and in this case coarser resolutions, 20 or $30 \mathrm{~km}$, in combination with range maps should be employed (Montesino Pouzols et al. 2014; Venter et al. 2014; Butchart et al. 2015); these resolutions represent a good compromise to reduce the effect of commission errors with only little increase in the total protected area selected. We recommend that conservation analyses are not performed at very coarse resolutions (e.g. $100 \mathrm{~km}$ or more), as these are likely to produce highly cost-inefficient spatial plans. Conservation is an applied discipline and scientists are increasingly seeking for costefficient PA plans (Carwardine et al. 2008a; Venter et al. 2014). Hence, keeping costs substantially low is more important than having a partial reduction in the uncertainty deriving from commission errors.

\section{Acknowledgements}

We thank Carlo Rondinini and the Global Mammal Assessment laboratory in Sapienza University of Rome for providing the species distribution models used in our analyses. We are grateful to the Editor, Céline Bellard and two reviewers, Franceso Ficetola and Boris Leroy, for their very useful comments.

\section{Data accessibility}

All the data used in this study derive from external sources:

The species distribution ranges were derived from the IUCN Red List of Threatened Species, available at http://www.iucnredlist.org/technicaldocuments/spatial-data.

The protected areas data were derived from the World Database on Protected Areas (WDPA), available at: www.protectedplanet.net.

The habitat suitability models were derived from the Global Mammal Assessment programme, available at: http://globalmammal.org/habitatsuitability-models-for-terrestrial-mammals

\section{References}

Ball, I.R., Possingham, H.P. \& Watts, M. (2009) Marxan and relatives: software for spatial conservation prioritisation. Spatial Conservation Prioritisation: Quantitative Methods and Computational Tools (eds A. Moilanen, K.A. Wilson \& H.P. Possingham), pp. 185-195. Oxford University Press, Oxford, UK.

Beresford, A.E., Buchanan, G.M., Donald, P.F., Butchart, S.H.M., Fishpool, L.D.C. \& Rondinini, C. (2011) Poor overlap between the distribution of protected areas and globally threatened birds in Africa. Animal Conservation, 14, 99-107.

Bontemps, S., Defourny, P., Bogaert, E.V., Arino, O., Kalogirou, V. \& Perez, J.R. (2011) GLOBCOVER 2009-Products description and validation report.

Boyd, C., Brooks, T.M., Butchart, S.H.M., Edgar, G.J., Da Fonseca, G.A.B., Hawkins, F. et al. (2008) Spatial scale and the conservation of threatened species. Conservation Letters, 1, 37-43.

Brooks, T., da Fonseca, G.A.B. \& Rodrigues, A.S.L. (2004) Species, data, and conservation planning. Conservation Biology, 18, 1682-1688.

Butchart, S.H.M., Clarke, M., Smith, R.J., Sykes, R.E., Scharlemann, J.P.W. \& Harfoot, M. et al. (2015) Shortfalls and solutions for meeting national and global conservation area targets. Conservation Letters, 8, $329-337$.

Carwardine, J., Wilson, K.A., Ceballos, G., Ehrlich, P.R., Naidoo, R., Iwamura, T., Hajkowicz, S.A. \& Possingham, H.P. (2008a) Cost-effective priorities for global mammal conservation. Proceedings of the National Academy of Sciences of the United States of America, 105, 11446-11450.

Carwardine, J., Wilson, K.A., Watts, M., Etter, A., Klein, C.J. \& Possingham, H.P. (2008b) Avoiding costly conservation mistakes: the importance of defining actions and costs in spatial priority setting. PLoS One, 3, e2586.

Ceballos, G., Ehrlich, P.R., Soberón, J., Salazar, I. \& Fay, J.P. (2005) Global mammal conservation: what must we manage? Science, 309, 603-607.

Clark, J.A. \& May, R.M. (2002) Taxonomic bias in conservation research. Science, 297, 191-192.

Di Marco, M. \& Santini, L. (2015) Human pressures predict species' geographic range size better than biological traits. Global Change Biology, 21, 2169-2178.

Di Marco, M., Brooks, T., Cuttelod, A., Fishpool, L.D.C., Rondinini, C., Smith, R.J. et al. (2016) Quantifying the relative irreplaceability of important bird and biodiversity areas. Conservation Biology, 30, 392402.

Faurby, S. \& Svenning, J.C. (2015) Historic and prehistoric human-driven extinctions have reshaped global mammal diversity patterns. Diversity and Distributions, 21, 1155-1166.

Ficetola, G.F., Rondinini, C., Bonardi, A., Katariya, V., Padoa-Schioppa, E. \& Angulo, A. (2014) An evaluation of the robustness of global amphibian range maps. Journal of Biogeography, 41, 211-221.

Gaston, K.J. \& Fuller, R.A. (2009) The sizes of species' geographic ranges. Journal of Applied Ecology, 46, 1-9.

GRASS Development Team (2014) Geographic Resources Analysis Support System (GRASS) Software, Version 6.4.4. Open Source Geospatial Foundation. http://grass.osgeo.org

Guisan, A., Tingley, R., Baumgartner, J.B., Naujokaitis-Lewis, I., Sutcliffe, P.R., Tulloch, A.I.T. et al. (2013) Predicting species distributions for conservation decisions. Ecology Letters, 16, 1424-1435.

Hurlbert, A.H. \& Jetz, W. (2007) Species richness, hotspots, and the scale dependence of range maps in ecology and conservation. PNAS, 104, $13384-13389$. 
IUCN (2015) The IUCN Red List of Threatened Species, Version 2015.2. Available at: www.iucnredlist.org

IUCN \& UNEP-WCMC (2015) The World Database on Protected Areas (WDPA) [version July 2015]. UNEP-WCMC, Cambridge, UK. Available at: www.protectedplanet.net

Jetz, W., Sekercioglu, C.H. \& Watson, J.E.M. (2008) Ecological correlates and conservation implications of overestimating species geographic ranges. Conservation Biology, 22, 110-119.

Jetz, W., Wilcove, D.S. \& Dobson, A.P. (2007) Projected impacts of climate and land-use change on the global diversity of birds. PLoS Biology, $\mathbf{5}, \mathrm{e} 157$.

Joppa, L.N., Butchart, S.H.M., Hoffmann, M., Bachman, S., Akçakaya, H.R., Moat, J. et al. (2015) Impact of alternative metrics on estimates of extent of occurrence for extinction risk assessment. Conservation Biology, 30, 362-370.

Juffe-Bignoli, D., Burgess, N.D., Bingham, H., Belle, E.M.S., de Lima, M.G., Deguignet, M. et al. (2014) Protected Planet Report 2014. UNEP-WCMC, Cambridge, UK.

Kark, S., Levin, N., Grantham, H.S. \& Possingham, H.P. (2009) Betweencountry collaboration and consideration of costs increase conservation planning efficiency in the Mediterranean Basin. PNAS, 106, 1536815373.

Lawler, J.J., Aukema, J.E., Grant, J.B., Halpern, B.S., Kareiva, P., Nelson, C.R. et al. (2006) Conservation science: a 20-year report card. Frontiers in Ecology and the Environment, 4, 473-480.

Maiorano, L., Amori, G., Capula, M., Falcucci, A., Masi, M., Montemaggiori, A. et al. (2013) Threats from climate change to terrestrial vertebrate hotspots in Europe. PLoS One, 8, e74989.

Margules, C.R. \& Pressey, R.L. (2000) Systematic conservation planning. Nature, 405, 243-253.

McCarthy, D.P., Donald, P.F., Scharlemann, J.P.W., Buchanan, G.M., Balmford, A., Green, J.M.H. et al. (2012) Financial costs of meeting global biodiversity conservation targets: current spending and unmet needs. Science, 338, 946-949.

Montesino Pouzols, F., Toivonen, T., Di Minin, E., Kukkala, A.S., Kullberg, P., Kuusterä, J. et al. (2014) Global protected area expansion is compromised by projected land-use and parochialism. Nature, 516, 383-386.

Naidoo, R. \& Iwamura, T. (2007) Global-scale mapping of economic benefits from agricultural lands: implications for conservation priorities. Biological Conservation, 140, 40-49.

National Imagery and Mapping Agency (1997) World miscellaneous water lines (VMAP0).

Orme, C.D.L., Davies, R.G., Olson, V.A., Thomas, G.H., Ding, T.-S., Rasmussen, P.C. et al. (2006) Global patterns of geographic range size in birds. PLoS Biology, 4, e208.

Pimm, S., Jenkins, C., Abell, R., Brooks, T., Gittleman, J.L., Joppa, L., Raven, P.H., Roberts, C.M. \& Sexton, J.O. (2014) The biodiversity of species and their rates of extinction, distribution, and protection. Science, 344, 1246752

Pineda, E. \& Lobo, J.M. (2012) The performance of range maps and species distribution models representing the geographic variation of species richness at different resolutions. Global Ecology and Biogeography, 21, 935-944.

Rahbek, C. (2005) The role of spatial scale and the perception of largescale species-richness patterns. Ecology Letters, 8, 224-239.

Rodrigues, A.S.L., Akcakaya, H.R., Andelman, S.J., Bakarr, M.I., Boitani, L., Brooks, T.M. et al. (2004) Global gap analysis: priority regions for expanding the global protected-area network. BioScience, 54, 1092 1100 .

Rondinini, C., Stuart, S. \& Boitani, L. (2005) Habitat suitability models and the shortfall in conservation planning for African vertebrates. Conservation Biology, 19, 1488-1497.

Rondinini, C., Wilson, K.A., Boitani, L., Grantham, H. \& Possingham, H.P. (2006) Tradeoffs of different types of species occurrence data for use in systematic conservation planning. Ecology Letters, 9, 11361145 .
Rondinini, C., Di Marco, M., Chiozza, F., Santulli, G., Baisero, D., Visconti, P. et al. (2011) Global habitat suitability models of terrestria mammals. Philosophical Transactions of the Royal Society of London B. Biological Sciences, 366, 2633-2641.

Secretariat of the CBD (2010) Conference of the Parties 10 Decision X/2. Strategic Plan for Biodiversity 2011-2020, 1-13.

USGS (2006) Shuttle Radar Topography Mission 3 arc second version 2.0 [WWW Document]. URL www.landcover.org/data/srtm

Venter, O., Fuller, R.A., Segan, D.B., Carwardine, J., Brooks, T., Butchart, S.H.M. et al. (2014) Targeting global protected area expansion for imperiled biodiversity. PLoS Biology, 12, e1001891.

Visconti, P., Di Marco, M., Álvarez-Romero, J.G., Januchowski-Hartley, S.R., Pressey, R.L., Weeks, R. \& Rondinini, C. (2013) Effects of errors and gaps in spatial data sets on assessment of conservation progress. Conservation Biology, 27, 1000-1010.

Watson, J.E.M., Dudley, N., Segan, D.B. \& Hockings, M. (2014) The performance and potential of protected areas. Nature, 515, 67-73.

Whittaker, R.J., Araújo, M.B., Jepson, P., Ladle, R.J., Watson, J.E.M. \& Willis, K.J. (2005) Conservation biogeography: assessment and prospect. Diversity and Distributions, 11, 3-24.

Wilson, K.A., Underwood, E.C., Morrison, S.A., Klausmeyer, K.R., Murdoch, W.W., Reyers, B. et al. (2007) Conserving biodiversity efficiently: what to do, where, and when. PLoS Biology, 5, e223.

Wilson, K.A., Evans, M.C., Di Marco, M., Green, D.C., Boitani, L., Possingham, H.P., Chiozza, F. \& Rondinini, C. (2011) Prioritizing conservation investments for mammal species globally. Philosophical Transactions of the Royal Society B: Biological Sciences, 366, 26702680

Received 23 April 2016; accepted 11 August 2016

Handling Editor: Céline Bellard

\section{Supporting Information}

Additional Supporting Information may be found in the online version of this article.

Fig. S1. Trade-off between total area prioritized for protection and aggregate level of species coverage under the three scenarios (perceived, realized and suitable) described in Table 1 and a 'random coverage' scenario.

Fig. S2. Spatial solutions to achieve species representation targets under the perceived and suitable scenarios at a resolution of $10 \mathrm{~km}$.

Fig. S3. Spatial solutions to achieve species representation targets under the perceived and suitable scenarios at a resolution of $50 \mathrm{~km}$

Fig. S4. Spatial solutions to achieve species representation targets under the perceived and suitable scenarios at a resolution of $200 \mathrm{~km}$.

Fig. S5. Performance of two planning scenarios in which the species distribution data were degraded to logic binary values of presence and absence.

Fig. S6. Trade-off between 'costs' of protected area (PA) expansion and aggregate level of species coverage (i.e. sum of species targets achieved) when employing different cost formulations. 